\title{
Empty Nose Syndrome: When the Nose Is Worse After Surgery
}

\author{
Murray Grossan, MD* \\ Department of Otolaryngology, Cedars Sinai Hospital Medical Towers, Los Angeles, USA
}

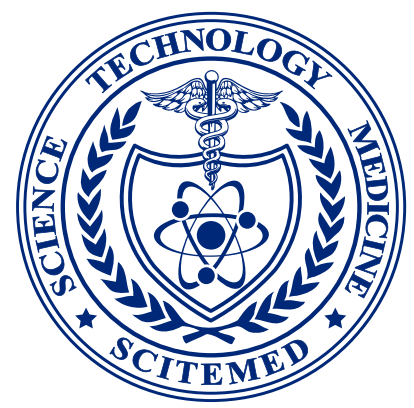

\section{Abstract}

It is normal to have impaired mucociliary clearance after any nasal/sinus surgery. Despite cleansing and antibiotics, infections may occur. However, in the patients with unusual distress, complaints of insufficient air, being unable to breathe - consider ENS - Empty Nose Syndrome.

Y our patient's history is that she had some difficulty breathing at night. The doctor diagnosed a deviated septum and recommended correcting it. She is seeing you now because 3 months after surgery, she isn't getting enough air! She says she can't breathe! You check her oxygen level and it is $99 \%$. You look into her nose and the septum is perfectly straight! In addition, there is more than enough room for air passage. Why is this patient complaining of not getting enough air? Does she have Empty Nose Syndrome (ENS) [1]?

Eugene Kern, M.D. had such a patient. When he took a CT of the sinuses, he saw that the inferior nasal turbinates had been removed. Even the middle turbinates were smaller. His student remarked that the nose looked empty - hence the name Empty Nose Syndrome or ENS [2].

The inferior turbinates have major functions that include warming the air on its way to the lungs; supplying an outer layer of mucus that traps bacteria, dust, pollens and toxins. It also supplies the inner layer with thin mucus that allows for synchronous beating of millions of cilia that act as oars, to move the mucus out of the nose to the back of the throat where it is swallowed $[3,4]$.

The turbinates also serve a neural function. They direct the flow of air so that it reaches sensors that tells the body that the air is flowing in correctly. With the turbinates absent, there is a significant change in air pressure reaching the sensors. A useful analogy is water from a hose with a nozzle of correct size opening. The stream travels four feet. Now, open the nozzle wide, and the water dips at your feet; it no longer reaches the roses. In a similar manner, when the nose is widely open, air currents no longer reach the sensors to tell the respiratory system that air is coming in. In addition, the pressure of the air reaching the lower respiratory system is altered, contributing to ENS symptoms [5].

\section{ENS and the Limbic System}

Recent studies have shown connections to the limbic system to explain the patient's distress. In addition, there are fibers from the Cranial Fifth Nerve that require activation, and therefore the absence of that pressure is distressing [5-7].

A useful analogy is anesthesia of the second finger. In trying to type, you can use that finger, but you no longer feel the keys. It is now difficult to type [8].

In ENS, there may be recurrent infection due to absence of mucociliary clearance. Without the blanket to trap bacteria and the cilia to move them, bacteria remain in place and multiply. Patients may feel symptoms due to absence of warm moist air. There may be hyposmia due to dryness. Crusting and infection are common. There are associated chest complaints because of the change in air pressure flow [9].

ENS is not unlike atrophic rhinitis, but without the surgical history. ENS must be differentiated from the frequent sinus infections after any nasal/sinus surgery that accompany reduced mucociliary clearance. However here, the turbinates are usually swollen $[10,11]$.

\section{Why to Remove the Turbinates?}

Logically, it makes sense: if the turbinates are enlarged, blocking the airway, by removing them you create a wider space for air flow. Unfortunately, the physiology of nasal function, is seriously altered, resulting in a distressed patient [12].

Turbinectomy can occur with cryosurgery, electrical cautery, laser and radiofrequency, and can result in excessive destruction of the turbinate. The result is excessive crusting and frequent infection.

Lemogne has recommended treating Empty Nose Syndrome as a somatic disorder, including cognitive therapy and by venlafaxine [13].

There have been many procedures used for reconstruction of the turbinates, and repairing the air flow recommended. Steven Houser of Cleveland has pioneered these procedures, including alloderm implant $[14,15]$.

One that is frequently used in injecting Hyaluronic acid gel into the turbinate area, as well as the septum. This may give months of temporary relief, but must be repeated about every six months. A further action of Hyaluronic acid is that you can inject this into the turbinate and septum to reestablish proper air current flow. This makes an excellent guide for possible surgical correction [16].

\section{Postoperative Impaired Cilia}

It is usual after any nasal surgical procedure to take time for the nose to return to normal mucociliary function. One study indicated three months. With the cilia impaired post- surgery, the normal bacterial defenses are reduced. Some doctors routinely give systemic antibiotics to prevent infection. We have found that using pulsed irrigation to restore cilia function post-op works well. With cilia function restored earlier, there is less infection and symptoms. Restoring mucociliary function may include saline spray, green tea, humming and overall increase of fluids with lemon/lime [17].

\section{ENS Therapy}

Because this condition is so variable and difficult to evaluate, there are many variations of treatment. The following are those I have found helpful.

- Cognition: often these patients come to me after being dismissed as cases of imagination. How can they complain of not being able to breathe when the nose is wide open and the $\mathrm{O} 2$ saturation registers at $99 \%$ ? A full explanation about air currents, dryness and somatic symptoms helps and reassures that patient. When they understand the physical reasons why they have their symptoms, this can bring significant relief; ideally they no longer increase their symptoms by anxiety reinforcement. 
- Recommendation for stress reduction are beneficial.

- Clear crusts and debris. Simple irrigation can be of benefit and reduce infection [18].

- Pulsed nasal irrigation is helpful. In addition to removing crusts and debris, the massage action brings fresh circulation to the area and is a useful substitute for the absent cilia action [4].

- Moisten the nose. Saline sprays are useful. Sprays with Lactated Ringer's formula are more physiologic. Breathe.ease XL is a Ringer's type solution.

- Cotton moistened with Breathe.ease XL can give relief. The patient learns to make just the right size, shape and thickness, to narrow the airway for comfort.

- Water Soluble Nasal Gel, such as Breathe.ease XI gel is useful at night. The pointed tip allows the patients to "mold" the right amount in the right place.

- Infection is common in ENS. I have found 2\% mupiricin ointment of particular value for infection

- Premarin Vaginal Cream is used to thicken the membrane in the vagina. I have used this for my patients in the nose with fairly beneficial results. The premarin thickens the membranes and increases mucus.

- If symptoms persist, injections of Hyaluronic Acid to improve the air flow are performed. Once the best location is established, a more permanent alloderm implant may be considered.

- Atrophic Rhinitis can occur independent of any surgical origin. However, the treatment is essentially similar.

- Many procedures have been used to correct air flow problems associated with ENS and atrophic rhinitis. As pointed out by Dr. Cottle, the benefits are not just to the nose, but to the pulmonary system as well [10].

- $\quad$ The system of treatment I have outlined has benefitted my patients. I would recommend considering this course for your patients.

\section{Article Information}

*Corresponding Author: Murray Grossan, MD

Board Certified Otolaryngology and Head and Neck Surgery, 8631 W. 3rd Street Suite 440 E, Cedars Sinai Hospital Medical Towers, Los Angeles, USA. Emails: ENTconsult@aol.com; drgrossan@yahoo.com

Received: Nov. 24, 2017; Accepted: Dec. 20, 2017; Published: Jun. 6, 2018

\section{DOI: 10.24983/scitemed.aohns.2018.00065}

Copyright (c) 2018 The Author(s). This is an open-access article distributed under the terms of the Creative Commons Attribution 4.0 International License (CC-BY).

\section{Funding: None}

\section{Conflict of Interest: None}

\section{References}

1. Coste A, Dessi P, Serrano E. Empty nose syndrome. Eur Ann Otorhinolaryngol Head Neck Dis 2012;129(2):93-97.

2. Chhabra N, Houser SM. The diagnosis and management of empty nose syndrome. Otolaryngol Clin North Am 2009;42(2):311-330.

3. Fadal RG. The medical management of rhinitis. In: English GM, ed. Textbook of Otolaryngology. vol 2. Philadelphia: JB Lippincott, 1991:125.

4. Tomooka LT, Murphy C, Davidson TM. Clinical study and literature review of nasal irrigation. Laryngoscope 2000;110(7):1189-1193.

5. Freund W, Wunderlich AP, Stöcker T, Schmitz BL, Scheithauer MO. Empty nose syndrome: limbic system activation observed by functional magnetic resonance imaging. Laryngoscope 2011;121(9):20192025.

6. Kuan EC, Suh JD, Wang MB. Empty nose syndrome. Curr Allergy Asthma Rep 2015;15(1):493.

7. Li C, Farag AA, Leach J, et al. Computational fluid dynamics and trigeminal sensory examinations of empty nose syndrome patients. Laryngoscope 2017;127(6):E176-E184.

8. Martin, C. Having nasal surgery? Don't you become an empty nose victim! Nashville, TN: Cold Tree Press; 2007.

9. Strohl KP, Butler JP, Malhotra A. Mechanical properties of the upper airway. Compr Physiol 2012;2(3):1853-1872.

10. Cottle M.H. Nasal atrophy, atrophic rhinitis, ozena: medical and surgical treatment: repair of septal perforations. J Int Coll Surg 1958;29(4):472-484.

11. Mabry RL. Therapeutic agents in the medical management of sinusitis. Otolaryngol Clin North Am 1993;26(4):561-570.

12. Scheithauer MO. Surgery of the turbinates and "empty nose" syndrome. GMS Curr Top Otorhinolaryngol Head Neck Surg 2010;9:Doc03.

13. Lemogne C, Consoli SM, Limosin F, Bonfils P. Treating empty nose syndrome as a somatic symptom disorder. Gen Hosp Psychiatry 2015;37(3):273.e9-10.

14. Houser SM. Empty nose syndrome associated with middle turbinate resection. Otolaryngol Head Neck Surg 2006;135(6):972-973.

15. Brown CL, Graham SM. Nasal irrigations: good or bad? Curr Opin Otolaryngol Head Neck Surg 2004;12(1):9-13.

16. Modrzyński M. Hyaluronic acid gel in the treatment of empty nose syndrome. Am J Rhinol Allergy 2011;25(2):103-106.

17. Proetz AW. Air currents in the upper respiratory tract and their clinical importance. Ann Otol Rhinol Laryngol 1951;60(2):439-467.

18. Olson DE, Rasgon BM, Hilsinger RL Jr. Radiographic comparison of three methods for nasal saline irrigation. Laryngoscope 2002;112:1394-1398. 